\title{
OS DESAFIOS DA PARTICIPAÇÃO E DA EFETIVAÇÃO DA CIDADANIA NA
} CONTEMPORANEIDADE ${ }^{1}$

\author{
Talita Kelly de Sousa Passos ${ }^{2}$ \\ Solange Maria Teixeira ${ }^{3}$
}

\section{RESUMO}

O presente artigo realiza uma reflexão teórica sobre os desafios da participação, em tempos de contrarreforma neoliberal que age a partir do desmonte das políticas sociais e esvaziamento do sentido mais amplo da participação, afetando o processo de materialização e expansão da cidadania no país. Contrariando a concepção clássica que analisa a formação dos direitos de cidadania no Brasil põe-se em relevo o processo de configuração desses direitos, ora produto das lutas sociais, ora estratégia de dominação de grupos dominantes do poder econômico e político. No cenário contemporâneo marcado pela regressão desses direitos, a categoria participação ainda continua sendo o principal instrumento para defesa da cidadania.

Palavras-Chave: Democracia. Participação. Cidadania.

\begin{abstract}
This paper presents a theoretical reflection on the challenges of participation, in times of neoliberal counter-reform that acts from the emptying of the broader meaning of participation, affecting the process of materialization and expansion of citizenship in the country. From classic bibliographic references that analyze the formation of citizenship rights in Brazil, we highlight the process of configuration of these rights, now the product of social struggles, now the strategy of domination of dominant groups of economic and political power. In the contemporary scenario marked by the regression of these rights, the participation category is still the main instrument for the defense of citizenship.
\end{abstract}

Keywords: Democracia. Participation. Citizenship.

\section{INTRODUÇÃO}

O presente artigo visa realizar uma reflexão teórica sobre os desafios da participação, em tempos de contrarreforma neoliberal que age a partir do desmonte das políticas sociais e do esvaziamento do sentido mais amplo dessa participação,

\footnotetext{
${ }^{1}$ Trabalho apresentado no Congresso Brasileiro Ciência e Sociedade (CBCS 2019), promovido pelo Centro Universitário Santo Agostinho, de 03 a 05 de outubro de 2019, em Teresina-PI.

${ }^{2}$ Mestrado em Políticas Públicas pela Universidade Federal do Piauí. Doutoranda em Políticas Públicas pela Universidade Federal do Piauí. E-mail: talitakelly18@hotmail.com

${ }^{3}$ Pós-Doutora em Serviço Social pela PUC-SP. Professora do Programa de Pós-Graduação de Políticas Públicas da Universidade Federal do Piauí. E-mail: solangeufpi@gmail.com.
} 


\section{conghESSO CIENCIAESOCIEDADE

afetando o processo de materialização e expansão da cidadania no país. Os direitos, sobretudo os sociais, construídos historicamente no país, seja por meio das lutas populares, seja pela negociação entre os diferentes setores da sociedade brasileira, encontram-se em estágio de instabilidade, marcado por retrocessos de ordens diversas, dificultando à sua efetivação. Para tanto, pretende-se desenvolver a análise a partir do seguinte questionamento: Como a redução dos canais de participação impacta na garantia dos direitos de cidadania, no atual cenário neoliberal?

$\mathrm{O}$ artigo encontra-se dividido em dois momentos: o primeiro tem como objetivo demonstrar como a cidadania foi construída no Brasil e quais são os impactos que esta vem sofrendo com a adoção das medidas neoliberais no país. De forma antagônica ao pensamento clássico da literatura e da história brasileira, defende-se que a participação e resistência das camadas populares sempre estiveram presentes na história do país, manifestando-se de diferentes formas, que nem sempre correspondiam à fala ou questionamentos explícitos, assim como nos sugere Perlatto (2015). Abordou-se ainda a discussão da categoria e as forças desestabilizadoras que a afetam no cenário da globalização e da insuficiência do Estado territorial moderno para efetivá-la, a partir de Lavalle (2003).

No segundo momento são sublinhadas as alternativas de autores como Dardot e Laval (2016), Miguel (2014) para a ampliação da democracia em tempos de neoliberalismo, além de serem analisadas as estratégias capitalistas para o esvaziamento da participação e da ação coletiva crítica. Recorre-se às reflexões de Dagnino, Olvera, Panfichi (2006) e Dagnino (2004) para a análise dos dois projetos em curso na cena contemporânea: o projeto democrático participativo e o projeto neoliberal. Este último compartilha os mesmos termos do primeiro, ocultando as diferenças que existem entre ambos, para reforçar sua estratégia de expansão e manutenção da ordem social vigente.

Conclui-se que o potencial da participação popular é imprescindível para a expansão democrática e efetivação da cidadania. Destarte, deve-se criar novas instituições e arenas democráticas, reforçando o papel das organizações populares existentes, para fins de fortalecimento da capacidade de reivindicação política das 


\section{congęESSO CIENCIAESOCIEDADE

classes populares. Além disso, deve-se buscar a criação de mecanismos que possam capturar os interesses desse segmento social muitas vezes não formalizados por meio da linguagem verbal.

\section{METODOLOGIA}

O presente artigo é produto das reflexões teóricas iniciais no processo de doutoramento do Programa de Pós Graduação em Políticas Públicas, cuja pesquisa se direciona para avaliação da participação e controle social no processo de construção e conformação do Sistema Único de Assistência Social no estado do Piauí. Parte-se das reflexões referentes à construção da cidadania no país e qual o papel da participação social nesse processo. $\mathrm{O}$ trabalho abordou as contestações em estudos mais recentes que rediscutem o posicionamento da sociedade brasileira. Assim, buscou-se analisar as possibilidades e desafios da participação para a materialização da cidadania diante do cenário neoliberal, tendo como principais aportes teóricos os autores Lavalle (2003), Dardot e Laval (2016), Miguel (2014), Dagnino, Olvera, Panfichi (2006) e Dagnino (2004).

\section{PARTICIPAÇÃO E CIDADANIA À BRASILEIRA}

Nesta seção pretende-se realizar uma reflexão sobre o papel da participação popular na construção da cidadania no Brasil, a partir da análise histórica do processo de efetivação desses direitos, além de identificar os limites enfrentados no atual cenário político com o esvaziamento dos canais de participação, no contexto neoliberal.

Diante das divergências teóricas que circundam a categoria em discussão, é consenso que os avanços obtidos no século XX no campo da cidadania, parecem estar comprometidos por forças desestabilizadoras de médio e longo prazo. Primeiro, nos campos macroinstitucionais ou estatais, com a vulnerabilidade financeira e migratória das fronteiras nacionais, a internacionalização econômica e a cessão parcial da 


\section{conghESSO CIENCIAESOCIEDADE

soberania, bem como, o aprofundamento pujante das desigualdades sociais. Soma-se ainda a redefinição da intervenção do Estado na esfera social. Um segundo conjunto de fatores desestabilizadores se refere à diferenciação social e as mudanças socioculturais, cujos fenômenos tem dificuldade de se expressar na linguagem universal. Como destaca Lavalle (2003, p. 81) esse quadro decorre do:

[...] o descrédito das grandes ideologias, a suspeição suscitada pelas categorias totalizadoras (Savater, 1989), a emergência e proliferação de identidades restritas (Zermeño, 1987), o desencanto da política (Tenzer, 1990), a multiplicação de formas associativas civis a reivindicarem novos princípios de representatividade (Dagnino, 2002), a proliferação da chamada política da diferença, entre outras manifestações.

Nesse cenário é evidente a contradição que vem se desenvolvendo entre a concepção tradicional de cidadania e a capacidade do Estado na provisão à equidade e universalidade de direitos já cristalizados. A cidadania vem sofrendo nos últimos anos uma ressignificação que exprime desafios presentes: o alargamento dessa cidadania direciona para a necessidade de redefinir os termos da convivência das sociedades democráticas e sua inflação normativa só demonstra a ausência de respostas e de alternativas para sua concretização material (LAVALLE, 2003).

Os desafios para efetivação da cidadania nos Estados territoriais modernos podem ser evidenciados na realidade brasileira, marcada desde seus primórdios por desigualdades e exclusões das mais diversas ordens. Contextualizando a cidadania em nível nacional, diferentemente da pirâmide proposta por Marshall ${ }^{4}$, a construção da cidadania essa pirâmide parece ter sido invertida: primeiro, vieram os direito sociais, depois, os políticos e, por fim, os direitos civis (CARVALHO, 2003).

No país sempre foi dada uma maior ênfase aos direitos sociais e na cultura orientada mais para o Estado do que para a representação, chamada por José Murilo de Carvalho de Estadania, em contraste com a cidadania. A participação popular até os anos 1930 se constituía em reação ao que considerava arbítrio das autoridades. Era uma cidadania em negativo, onde a participação política nacional ficava restrita a

\footnotetext{
${ }^{4}$ Autor liberal, que a partir da análise da história europeia demonstra que cidadania foi construída pela sistematização dos direitos de forma sequencial em civis, políticos e sociais.
} 


\section{conghESSO CIENCIAESOCIEDADE

pequenos grupos, inclusive, nos grandes acontecimentos políticos nacionais. O povo tinha uma relação de distância com o governo (CARVALHO, 2003).

Wanderlei Guilherme dos Santos (1994) acrescenta ainda que durante o período 1930 a 1980, o Brasil vivenciou a ordem regulada, onde o Estado passou a intervir na produção econômica e na questão social para fins de legitimação e cooptação dos trabalhadores. Vivenciava-se a cidadania regulada, que dependia do reconhecimento formal por parte do Estado da profissão exercida pelo indivíduo.

Pesquisas mais recentes criticam os estudos dos historiadores clássicos, que concebem a participação da grande massa da população sob o prisma do "paradigma da ausência", em que os setores populares seriam "bestializados, passivos e pouco afeitos à sociabilidade e à organização" (PERLATTO, 2015, p. 134). Esses estudos recentes desenvolveram um novo paradigma, o "paradigma da agência", que demonstra que os setores subalternos se organizavam de diferentes formas e meios, para resistir, para criar novas alternativas diante da ordem opressora, que muitas vezes sem força expressiva dos argumentos, utilizavam de performances, da linguagem dos sentimentos e das formas não-verbais da comunicação (PERLATTO, 2015).

Entendendo que a esfera pública se constituiu como categoria importante para a reflexão de democracia no Brasil, a partir dos estudos realizados nas décadas de 1980 e 1990, Perlatto (2015) defende a hipótese de que a esfera pública brasileira, ao lado do Estado e Mercado, se configurou no Brasil desde o século XIX, diferentemente do que apontava os estudos que tratavam da historiografia brasileira, que concebiam sua constituição somente a partir do final do século XX. O autor demonstra que existiam duas esferas públicas que foram desenvolvidas concomitantemente: a seletiva e a subalterna. A primeira foi marcada pela seletividade dos personagens que nela podiam operar e aos temas a serem debatidos em seu espaço. A segunda foi marcada por diferentes espaços de sociabilidade em que permitiam a organização dos segmentos subalternos. As duas esferas não se configuraram de maneira isolada, mas se relacionavam tanto de forma dialógica, como conflituosa.

Ao demonstrar por meio da história brasileira, as possibilidades de resistência e organização dos grupos subalternos, desde o período imperial ao período de 


\section{conghESSO CIENCIAESOCIEDADE \\ Inovação, Diversidatie e Sustentahililitade}

redemocratização, Perlatto (2015) defende a necessidade de ampliação da democratização da esfera pública que não deve se orientar apenas por meio da institucionalização de procedimentos democráticos com vistas a proporcionar argumentos "racionais", mas tornar essa esfera mais porosa as manifestações, valores, demandas e reivindicações dos setores subalternos. O maior desafio evidenciado pelo autor se refere à construção de estruturas específicas que possam capturar tais interesses, que são expressos não só por argumentos, mas por meio de perfomances, da linguagem dos sentimentos e das formas não-verbais de comunicação, com a finalidade de uma "verdadeira política de transformação do país" (PERLATTO, 2015, p. 141).

\section{POSSIBILIDADES DA PARTICIPAÇÃO E A GARANTIA DOS DIREITOS DE CIDADANIA EM TEMPOS DE NEOLIBERALISMO}

Falar de participação e cidadania nos remete a discussão de democracia, por meio da qual é possível a construção de direitos numa perspectiva antagônica as características elitistas e excludentes das democracias eleitorais. A democracia participativa, elencada por este artigo, parte do aprofundamento da participação dos cidadãos.

Sob essa ótica, evidencia-se o papel da sociedade civil na construção da democracia, marcada por uma diversidade de atores civis, formatos institucionais e pluralidade de práticas e projetos políticos, se constituindo em um território de disputas e conflitos. Ao longo dos anos esta assumiu diferentes perspectivas, que vai desde a concepção virtuosa conflitante com o Estado "encarnação do mal" ao papel de parceira deste último. Bastou mudar a visão do Estado de inimigo para ente cooperador para que se construísse um contexto de despolitização, considerando o desaparecimento do conflito entre Estado e Sociedade Civil (DAGNINO; OLVERA; PANFICHI, 2006).

Dagnino, Olvera e Panfichi (2006) analisam o debate contemporâneo sobre democracia na América Latina, na perspectiva de resignificação da ideia de democracia 


\section{conpeESSSOCIENCIAESOCIEDADE

a partir da qual é possível um novo projeto de extensão e generalização dos direitos, marcado pela disputa de projetos políticos diferentes. Entre os projetos analisados, os autores utilizam o projeto democrático participativo e o projeto neoliberal de amplas áreas das políticas públicas. Embora ambos utilizem os mesmos conceitos e apelem para discursos semelhantes, são totalmente distintos.

Dagnino (2004) defende que estes dois projetos políticos estão em disputa no processo de construção democrática no Brasil e na América Latina, situação definida pela autora como confluência perversa: de um lado, o projeto neoliberal, se direciona de forma agressiva aos países da América do Sul, com orientações voltadas para a reestruturação e redução do Estado, em especial no campo social e, do outro, o projeto democratizante e participativo, produto das crises dos regimes autoritários e dos esforços nacionais voltados para o estímulo democrático.

O confronto entre esses dois projetos pode ser visualizado na disputa de significados para referências comuns (participação, sociedade civil, cidadania e democracia) que obscurece as diferenças e antagonismos existentes entre elas. Observa-se a mudança na relação Estado-sociedade civil, esta última tem sido utilizada cada vez mais com o sinônimo de Organizações Não-Governamentais (ONGs) ou de Terceiro Setor, entendidos como parceiros ideais do Estado para a transferência de suas responsabilidades (DAGNINO, 2004).

Considerando a incapacidade do Estado de atuar de forma eficaz em todas as áreas sociais e a obtenção de parcos resultados positivos por essas instituições, as mesmas passam a ser reconhecidas como representantes da sociedade civil. A participação também sofre com esse processo de deslocamento de significados, e passa a se resumir a participação solidária, cuja ênfase recai no trabalho voluntário e na responsabilidade social de indivíduos e empresas. A adoção dessa perspectiva se torna capaz de substituir o significado coletivo da participação social (DAGNINO, 2004).

Neves (2016) destaca que práticas antidemocráticas, reforçadas pelo clientelismo, pelo patrimonialismo e pelo autoritarismo do Estado tendem a se constituir em uma ameaça para a democracia tanto participativa como representativa no século XXI. Sob a égide neoliberal, marcada pela recessão e crise do capitalismo, 


\section{conghESSO CIENCIAESOCIEDADE

tais práticas ampliam sua abrangência e comprometem o Estado Democrático de Direitos, em cuja formação social os direitos são travestidos de favores. A participação democrática, de acordo com Alves (2016), é inibida pelo projeto neoliberal, tendo em vista que este advoga instigando a redução do Estado, transferindo a responsabilidade das ações, sobretudo, no âmbito social, para a sociedade civil.

Dois movimentos contraditórios foram visualizados no período de redemocratização brasileiro, ao mesmo tempo em que amplos setores da sociedade participavam ativamente dos espaços públicos reivindicando por melhorias nas diversas dimensões da vida em sociedade, temerosos pela atuação do Estado, que em período anterior limitava a liberdade do cidadão, observou-se ainda o movimento de contrarreforma neoliberal que ao evocar a sociedade para participar das ações, no âmbito social, em especial, procurava promover a substituição do Estado diante das expressões da questão social, retraindo os investimentos em políticas sociais e investindo cada vez menos nos serviços sociais. Novos paradigmas foram adotados, dentre eles, a focalização que assumiu o lugar da universalidade dos direitos.

O resultado dessa retração estatal foi o aprofundamento de problemáticas sociais que perpassam a realidade brasileira desde suas origens, evidenciando de maneira expressiva o abismo que separa a grande massa da população de uma minoria privilegiada. A redução dos canais de participação e o esvaziamento de seu significado possibilitaram os retrocessos vivenciados nos direitos de cidadania. De acordo com Behring (2009, p.13):

Do ponto de vista político, observa-se uma crise da democracia (WOOD, 2003), com visível esvaziamento das instituições democráticas, por uma lógica economicista, autoritária e tecnocrática, assumida pelos poderes executivos, cuja maior expressão são as práticas decretistas. No terreno da cultura, vê-se o aprofundamento do individualismo, do consumismo e do pensamento único.

Sob este aspecto, Dardot e Laval (2016) analisam a estrutura do neoliberalismo e o papel da esquerda nessa racionalidade. Os autores defendem a criação de uma nova racionalidade cuja conduta deve ser a direção para a construção de uma nova sociedade, considerando que na contemporaneidade governos de esquerda que adotaram elementos do capitalismo, mesmo que de forma inconsciente, não 


\section{conghESSO CIENCIAESOCIEDADE

obtiveram muito êxito. A democracia na perspectiva da hegemonia neoliberal encontra-se degradada e se institui mais como uma formalidade.

Considerando que a existência e alargamento da democracia é favorável para o estabelecimento e efetivação da cidadania, utiliza-se o pensamento de Vieira (2001, p. 44), na concepção de cidadania não restrita apenas como "um conjunto de direitos formais, mas como um modo de incorporação de indivíduos e grupos ao contexto social". É necessário apreender que cidadania, no atual cenário, ao mesmo tempo em que pressupõe igualdade formal também evidencia desigualdades substanciais.

Para entender os desafios e limites para o aprofundamento da democracia, segundo Miguel (2014), é necessário compreender a dinâmica da representação política e como a mesma se relaciona com as diferentes assimetrias presentes na sociedade. A representação, segundo a vertente hegemônica na teoria democrática, se desenvolve num contexto de combate ao elitismo, entretanto, a sua adaptação às premissas elitistas no cenário atual reduz as possibilidades do projeto democrático que fica submetido a uma ordem social dividida entre a minoria que governa e a maioria que é governada.

Sob essa ótica é necessário o alargamento do entendimento da representação política, no contexto de crise de legitimidade das instâncias representativas, para além do momento "formal" que se refere à delegação do poder decisório. Assim, a representação deve ser compreendida também a partir de outras duas dimensões: a constituição da agenda e do debate político e do processo de formação das preferências e das identidades coletivas (MIGUEL, 2014).

Nesse contexto, mesmo diante da crise da accoutability, que é o controle dos representados sobre os representantes, originada tanto pelas características das próprias instituições representativas como pelas influências de interesses especiais, a solução ainda se apresenta por meio da ampliação dessa supervisão. Para Miguel (2014) a representação local política numa sociedade desigual revela que a representação e democracia são territórios em disputa, já que podem se organizar em arranjos para a manutenção das assimetrias e das relações de dominação ou podem se direcionar em sentido contrário para combatê-las. 


\section{congęESSO CIENCIAESOCIEDADE

\section{CONSIDERAÇÕES FINAIS}

O projeto neoliberal se expandiu de forma pujante nos países da América Latina, em especial no Brasil, a partir de 1990. É uma racionalidade que se estende aos diversos âmbitos da vida em sociedade, extrapolando a dimensão econômica. Com o seu desenvolvimento, observa-se um profundo declínio e esvaziamento da participação e, consequentemente, da cidadania, que em nome da flexibilização não alarga o campo da efetivação de direitos básicos de um cidadão, sobretudo, no campo social.

A própria globalização, que acompanha o projeto em destaque, nos leva a repensar na promoção dessa cidadania que não pode mais ser efetivada dentro dos limites dos Estados territoriais modernos, que tem sua autonomia também limitada pelo capital internacionalizado. Além desses fatores, soma-se os processos de diferenciação social e mudanças socioculturais. Inúmeros são os desafios encontrados no cenário contemporâneo quando se discute democracia, participação e cidadania. Longe de esgotar as possibilidades de respostas ao questionamento realizado no início deste trabalho e que nos direcionou para a discussão realizada, objetiva-se contribuir e incentivar novas reflexões em torno da temática.

Diferentemente da abordagem clássica da literatura e da história brasileira, que entende a participação do povo distante dos principais fatos do país, os novos estudos e pesquisas demonstram que sempre existiu resistência. Resistência que ultrapassa o movimento explícito de contestação nos espaços públicos, mas que cria estratégia de sobrevivência diante de cenários autoritários, repressivos e punitivos. O brasileiro sempre se adaptou a cenários hostis, de supressão da fala, para se posicionar contra contextos sociais de grande ônus para a grande massa da população, seja por meio da música, da dança, da cultura popular, seja pelos "recados" deixados em muros e outros espaços de grande visibilidade.

Assim, em consonância com os autores abordados ao longo dessa discussão, acredita-se no potencial da participação popular para a expansão democrática e 


\section{conpeESSSOCIENCIAESOCIEDADE

efetivação da cidadania. Isto posto, além da criação de novas instituições e arenas democráticas - que reforçam o papel das organizações populares existentes, para fins de fortalecimento da capacidade de reivindicação política das classes populares deve-se buscar a criação de mecanismos que possam capturar os interesses desse segmento social muitas vezes não formalizados por meio da linguagem verbal.

A representação também discutida neste trabalho, diante da crise em que enfrenta de desconfiança e de ingovernabilidade, deve ser repensada para além do aspecto formal, com a finalidade de direcionar a sociedade para uma nova história de luta contra a manutenção das desigualdades, onde forças históricas de dominação continuam a persistir.

\section{REFERÊNCIAS}

ALVES, Maria da Conceição. Participação, democracia e direitos da cidadania: aproximação conceitual ao debate contemporâneo. NEVES, Angela Vieira (Org.).

Democracia e Participação Social: Desafios Contemporâneos. Campinas: Papel Social, 2016.

BEHRING, Elaine Rossetti. Política Social no contexto da crise capitalista. In: CFESS/ABEPSS. Serviço Social: Direitos sociais e competências profissionais. Brasília: CFESS/ABEPSS, 2009.

CARVALHO, José Murilo de. Cidadania no Brasil: o longo caminho. 11. Ed. Rio de Janeiro. Civilização Brasileira, 2003.

DAGNINO, Evelina. Construção democrática, neoliberalismo e participação: os dilemas da confluência perversa. Política \& Sociedade, n. 5, out. 2004, p. 139- 164. ; OLVERA, Alberto Javier; PANFICHI. Aldo. A disputa pela construção democrática na América Latina. São Paulo: Paz e Terra. UNICAMP, 2006.

DARDOT, Pierre; LAVAL, Christian. A nova razão do mundo: ensaio sobre a sociedade neoliberal. São Paulo: Boitempo, 2016.

LAVALLE, Adrián Gurza. Cidadania, Igualdade e Diferença. Lua Nova. São Paulo: CEDEC, n. 59, p. 75-94, 2003. 


\section{MOMGESSO CIENCIAESOCIEDADE}

MIGUEL, Luis Felipe. Democracia e Representação: territórios em disputa. 1. ed. São Paulo: Editora Unesp, 2014.

NEVES, Angela Vieira. Ameaças à democracia hoje: desafios contemporâneos. NEVES, Angela Vieira (Org.). Democracia e Participação Social: Desafios Contemporâneos. Campinas: Papel Social, 2016.

PERLATTO, Fernando. Seletividade da esfera pública e esferas públicas subalternas: disputas e possibilidades na modernização brasileira. Revista de Sociologia e Política. v. 23. n. 53. p. 121-145. mar. 2015.

SANTOS, Wanderlei Guilherme dos. Cidadania e justiça: a política social na ordem brasileira. 3. ed. Rio de Janeiro: Campus, 1994.

VIEIRA, Liszt. Notas sobre o conceito de cidadania. Revista Brasileira de Informação Bibliográfica em Ciências Sociais. São Paulo, n. 51, 1. sem, p.35-47, 2001. 